\title{
Effect of educational program based on planned behavior theory on preventive behaviors of sexually transmitted diseases of married women
}

Fatemeh Shamsolahi ${ }^{1}$, Seyedeh Tahereh Mirmolaei ${ }^{2}$, Amir Kasaeian $^{3,4,5}$, Hadi Ranjbar ${ }^{6}$, Maryam Modarres ${ }^{7}$

${ }^{1}$ Tehran University of Medical Sciences, Iran

${ }^{2}$ Midwifery and Reproductive Health Department, Tehran University of Medical Sciences, Tehran, Iran

${ }^{3}$ Hematology, Oncology and Stem Cell Transplantation Research Center, Research Institute for Oncology, Hematology and Cell Therapy, Tehran University of Medical Sciences, Tehran, Iran

${ }^{4}$ Digestive Diseases Research Center, Digestive Diseases Research Institute, Tehran University of Medical Sciences, Tehran, Iran ${ }^{5}$ Inflammation Research Center, Tehran University of Medical Sciences, Tehran, Iran

${ }^{6}$ Mental Health Research Center, Psychosocial Health Research Institute, Iran University of Medical Sciences, Tehran, Iran ${ }^{7}$ Nursing and Midwifery Care Research Center, School of Nursing and Midwifery, Midwifery and Reproductive Department, Tehran University of Medical Sciences, Tehran, Iran

\begin{abstract}
Introduction: Sexually transmitted diseases (STDs) are among the most common infectious diseases in women. The aim of the present study was to determine the effect of teaching based on theory of planned behavior on preventive behaviors of STDs of married women.

Material and methods: Study subjects consisted of 114 women who attended a university-affiliated hospital in Tehran, Iran. They were randomly assigned into intervention group $(n=58)$ and control group $(n=56)$. Women in intervention group participated in a four-session educational program based on a theory of planned behavior. Women in control group received a routine education. Data-gathering tool was a researcher-made questionnaire, including demographic characteristics, knowledge on sexually transmitted diseases, attitude, subjective norms, perceived behavioral control, and intention for healthy behavior along with self-reported sexual behaviors. Data was analyzed using repeated measure ANOVA.

Results: All constructs of the theory of planned behavior along with the knowledge and reported sexual behaviors improved significantly in intervention group in comparison to controls. The theory of planned behavior was effective in the increase of knowledge and improvement of attitude, subjective norms, perceived behavioral control, and intention for healthy behaviors in married women. It was also effective in improving healthier sexual behaviors.

Conclusions: Education program based on the theory of planned behavior was effective on preventive behaviors of STDs of married women. We recommend using this theory in prevention programs for sexually transmitted diseases in married women.
\end{abstract}

HIV AIDS Rev 2021; 20, 4: 294-301

DOI: https://doi.org/10.5114/hivar.2021.111544

Key words: sexually transmitted diseases, sexually transmitted infections, STDs, STIs, knowledge, attitude.

Address for correspondence: Maryam Modarres,

Nursing and Midwifery Care Research Center,

School of Nursing and Midwifery, Midwifery and Reproductive Department, Tehran University of Medical Sciences, Tehran, Iran, e-mail: modarres@tums.ac.ir
Article history:

Received: 22.02.2021

Received in revised form: 16.03 .2021

Accepted: 19.03.2021

Available online: 30.11 .2021
International Journal of HIV-Related Problem

HIV \& AIDS $R$ e $v$ i e w 


\section{Introduction}

Sexually transmitted diseases (STDs) are among the most common infectious diseases worldwide [1]. Every day, more than one million people around the world are infected with one of STDs [2]. According to the World Health Organization, the number of people infected with these infections is increasing. It is estimated that each year about 448 million people (men and women aged 15-49) are infected with sexually transmitted infections worldwide [2]. The prevalence of STDs in Iran has also increased, especially among women. Reports indicate that the rate of HIV transmission through sexual relationship has increased from 10 percent to $38.9 \%$ in Iran, and the rate of HIV among Iranian women increased also. One-third of HIV new cases in Iran in 2013 were women. The prevalence of hepatitis was $2.2 \%$, genital warts $7.7 \%$, and genital herpes $6.5 \%$ among women, which has increased compared to previous reports [3].

Since these diseases do not cause immunity, it is possible for each person to be infected several times during lifetime [4]. Risk factors include having multiple sexual partners, starting sexual activity at early age, poverty, smoking, low awareness, low literacy, depression, risky sexual behavior, and history of other sexually transmitted diseases [5]. Although treatments were developed for most of these diseases during the past century, these infections remain a public health problem, both in developing and developed countries [6]. STDs are the leading causes of other health problems, with serious medical and psychological consequences, including infertility, acute pelvic inflammatory disease, ectopic pregnancy, cancer, congenital infections, long-term acute disability, and even death [7]. Diseases that do not have a definitive cure, such as the herpes virus, can have a heavy burden on women, men, and children in terms of infection and mortality [8]. These infections also create a high-level of social stigma that makes them even more difficult to prevent and treat [9]. Furthermore, many of these diseases are symptomless for a long time, which increases the risk of their transmission. Since some of these diseases do not have vaccines, and several of them can transmit while the patient is symptomless, conventional methods of prevention, such as vaccinations, are not very effective in their prevention [10]. Therefore, behavioral approaches have been recommended to avoid these diseases.

Theory of planned behavior (TPB) is a well-known approach, which was introduced by Azien and Fishbein [11] in 1980. The model was further developed by Ajzen [12], Ajzen and Madden [13], and Ajzen [14]. Based on this theory, the main cause of a behavior is the intention to proceed. Intention is influenced by three independent structures, such as attitudes, subjective (social) norms, and perceived behavioral control. TPB model is presented in Figure 1.

Attitude reflects a person's positive or negative evaluation of a behavior. Subjective norms imply that perceived social pressures may lead to performing or not performing certain behaviors. Perceived behavioral control is the belief about difficulty of performing a particular behavior. Based on this theory, a positive attitude towards a behavior, significant affirmation of behavior by others (subjective norms), and a sense of having control over the behavior (perceived behavioral control) are effective in the appearance of a certain behavior [11-14]. Prevention of sexually transmitted diseases requires strong control over behaviors, which are under influence of people's attitudes, subjective norms, and their perception of having control over them [15-18].

The effectiveness of educational programs based on TPB was investigated in several studies. Moeini et al. [19] conducted a study to examine effectiveness of a theory of planned behavior-based educational program on the improvement of safe sexual behaviors among male substance abusers. Their results showed that this educational program was effective in improvement of attitude, subjective norms, perceived behavioral control, and behavioral intention on safe sexual behaviors. Results of a study conducted by Guan et al. [16] showed that TPB-based education was effective in condom negotiation self-efficacy among African-American women. In another study in Korea, results showed that TPB was a suitable model in explanation health behaviors of single-women with sexual experience [20]. However, results of some research have shown that this model had not been very effective in changing sexual behaviors. A study conducted by Shepherd et al. [21] reported that self-efficacy was not a predictive of adolescents' sexual behaviors or condom using. Their results showed that comprehensive education based on TPB was not more effective than abstinence-only education in recent sexual behaviors of students. Moreover, a study of Turchik et al. [22] among 453 American undergraduate students showed that TPB-based model did not adequately influenced prediction of sexual risk behaviors.

The importance of healthy sexual behaviors in prevention of STDs was confirmed in several studies. Attitudes, social norms, and having control on behavior have all shown to be effective in the control of high-risk behaviors. Being married usually is a predictor of better sexual behaviors, and married women were not the subject of such studies. However, results of several studies showed that married women are at risk of STDs and HIV. Factors, including social support and socio-economic status, can predict this vulnerability. Married women with low-social support and

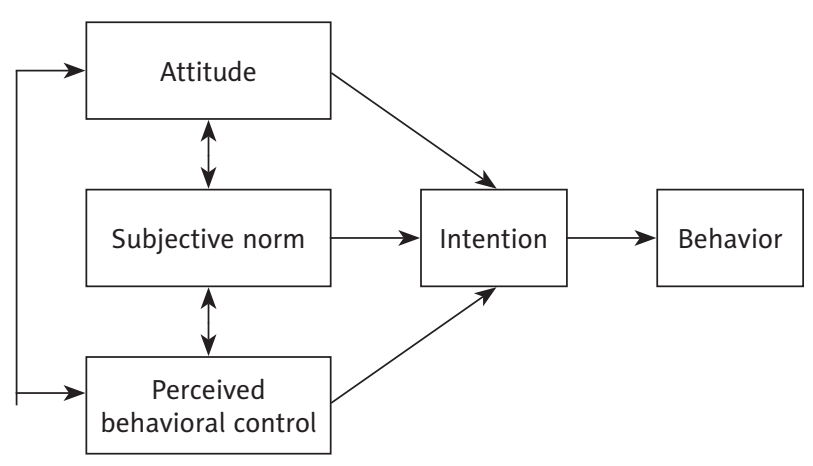

Figure 1 . Theory of planned behavior 
low-socio-economic status are at risk of developing STDs $[23,24]$. At the same time, attention to the health of married women and stay-at-home spouses has increased in recent years. They are the backbone of the family, and their health affects the health of all family members. Moreover, their sexual health affects the health of their spouses and children.

This study was designed to assess the effectiveness of an educational program based on TPB on preventive behaviors of sexually transmitted diseases of women.

\section{Material and methods}

This study was a randomized clinical trial, which was conducted from April 2018 to December 2018.

\section{Samples and setting}

The study was conducted at Ziaeian Hospital, Tehran University of Medical Sciences, Tehran, Iran. Study population involved all women who attended the hospital during the study period. Minimum sample size was determined $(n=49)$, using following formula, where $\alpha=0.05$ and $\beta=0.2$. Because we used a researcher-made scale for data gathering to calculate sample size, first, a pilot study was performed with two groups $(n=25)$ of subjects of the study population. The mean and standard deviation of two groups were used in the following formula: $\mathrm{S} 1=9.59, \mathrm{~S} 2=11.75, \mu 1=27.78, \mu 2=34.83$. Inclusion criteria were being married, not having known mental or physical illness, and being literate. Exclusion criteria were no consent to participate in the study, having a known physical or mental illness, being illiterate, being single, absence of more than one session in the educational intervention. All women who fulfilled inclusion criteria were assessed for eligibility. Among eligible subjects, women who completed and signed written informed consent form were included in the study. Random assignment was conducted using sealed-envelope method. Sealed envelopes were prepared by a statistician who was not present at study site. Data gathering and analyzing was conducted separately. Women in intervention group participated in four sessions of group-based education.

\section{Intervention}

The intervention was an educational program based on the planned behavior theory. Three sessions were planned for women, and one session was planned for their spouses. All sessions were performed by a consoler who was trained in the field of education. Each training session lasted 75 minutes. The content of program was developed by a research team based on research objectives and the planned behavior theory using a literature review. The content was approved by three faculty members of the Tehran University of Medical Sciences, who were expert in health education and sexual transmitted diseases. Women in control group received conventional education. The contents of all sessions are listed in Table 1.

\section{Data gathering}

Data were collected in three stages. First data collection was conducted before the intervention. Second measurement was performed at the end of intervention (one month in control group). Follow-up measurement was done two months later. The sampling and process of data collection are presented in Figure 2.

\section{Measurements}

Data was collected using a four-part scale, which was developed by a research team based on the theory

Table 1. Theme, content, and aim of educational program sessions

\begin{tabular}{|c|c|c|c|}
\hline Session number & Theme & Content & Aim \\
\hline One & $\begin{array}{l}\text { Sexually transmitted } \\
\text { diseases and } \\
\text { participants attitude }\end{array}$ & $\begin{array}{c}\text { Types of sexually transmitted diseases } \\
\text { Ways of STDs transmissions } \\
\text { Participants' attitudes and beliefs toward } \\
\text { STDs }\end{array}$ & $\begin{array}{l}\text { Increase of the knowledge } \\
\text { and strengthen participants' } \\
\text { attitudes toward disease } \\
\text { prevention behaviors }\end{array}$ \\
\hline Two & Sexual health in women & $\begin{array}{l}\text { Preventive behaviors against sexually } \\
\text { transmitted diseases } \\
\text { The importance of preventive behaviors } \\
\text { The role of the spouse in preventive behaviors }\end{array}$ & $\begin{array}{l}\text { Familiarizing the participants } \\
\text { with the role of subjective } \\
\text { norms in preventive behaviors }\end{array}$ \\
\hline Three & $\begin{array}{c}\text { Promotion of spouse } \\
\text { cooperation }\end{array}$ & $\begin{array}{l}\text { Types of sexually transmitted diseases } \\
\text { Ways of STDs transmissions } \\
\text { The role of the spouse in preventive behaviors }\end{array}$ & $\begin{array}{l}\text { Strengthening the role of } \\
\text { spouses (one of the subjective } \\
\text { norms) in the preventive } \\
\text { behaviors }\end{array}$ \\
\hline Four & $\begin{array}{l}\text { Empowerment to } \\
\text { perform preventive } \\
\text { behaviors }\end{array}$ & $\begin{array}{c}\text { Review the least sessions contents } \\
\text { Benefits of preventing behaviors } \\
\text { Understanding the obstacles of preventive } \\
\text { measures and how to overcome them }\end{array}$ & $\begin{array}{l}\text { Familiarizing the participants } \\
\text { with the role of perceived } \\
\text { behavioral control and } \\
\text { increasing women intention }\end{array}$ \\
\hline
\end{tabular}




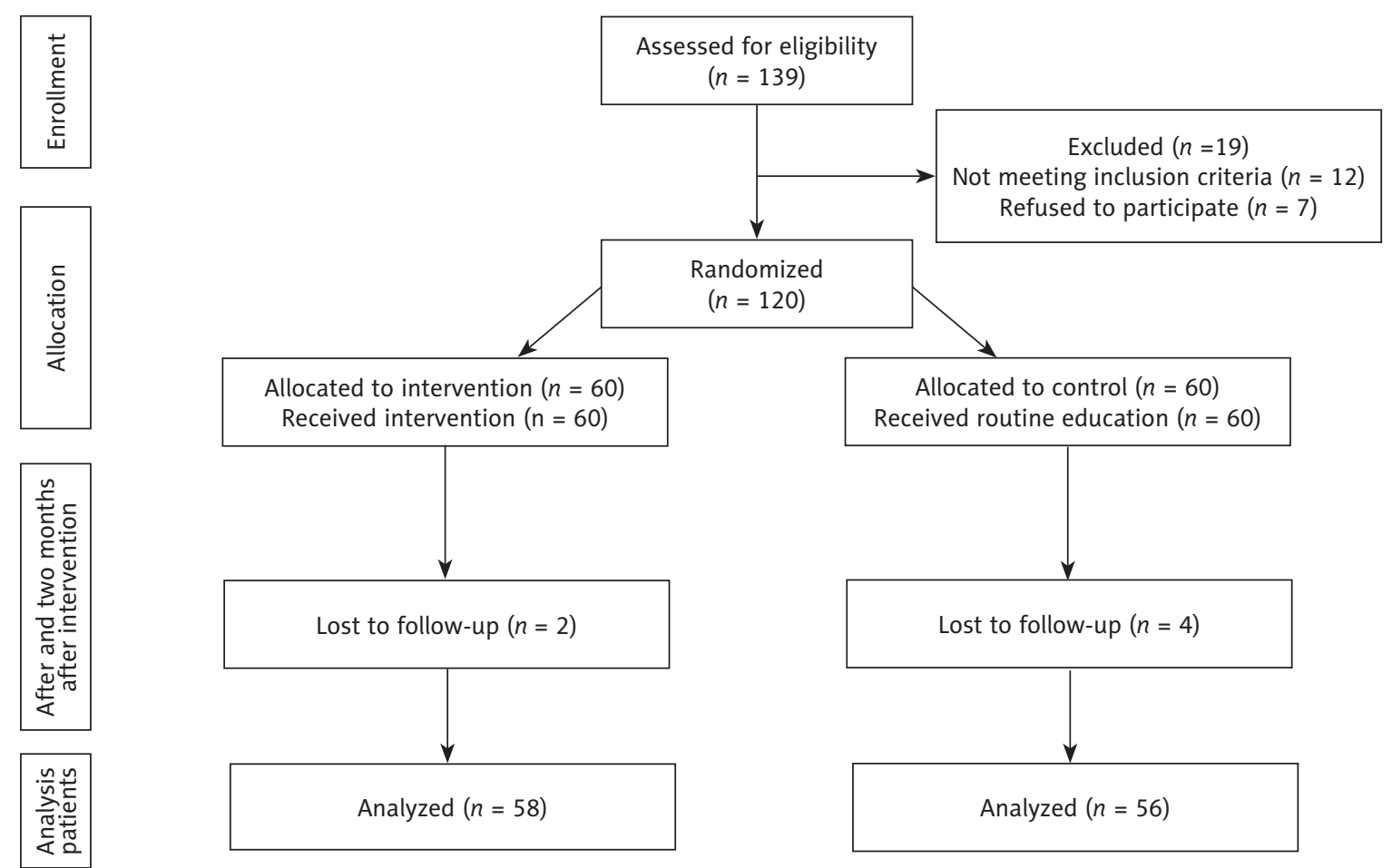

Figure 2. The recruitment, intervention and follow up diagram

of planned behavior. First part included socio-demographic information. Scale (education level, job's status, perception of family income, and number of pregnancies), and in second part, a 22-items scale was implemented, which was used to assess the knowledge of women about STDs. There was a possible 1 point for each question; 1 point if the answer was correct and 0 if it was incorrect. The scale scored between 0 and 22. Higher scores indicated higher knowledge on STDs.

Third part of the scale was based on components of the planned behavior theory. It consisted of four parts, including: attitude (10 items), subjective norms (10 items), perceived behavioral control (11 items), and intention (5 items). Each item was scored based on a five-point Likert scale, ranging from 1 ('strongly agree') to 5 ('strongly disagree'). Fourth part was an eighteen-items scale on preventive behaviors of sexually transmitted diseases. First seventeen items were scored based on a 5-points Likert scale, ranging from 1 ('never') to 5 ('always'). The last item was about vaccination, and it was scored as follows: 'never vaccinated' (0), 'once' (1), 'twice' (2), and 'three times' (3). This part scored between 18 and 89. Higher scores indicated higher level of protective behaviors. All four scales were developed for this study. First, a comprehensive review of related literature was conducted. An item pool was developed based on the planned behavior theory. All questions were reviewed and revised in a meeting of the research team.

\section{Content validity}

Content validity ratio (CVR), content validity index (CVI), and face validity were applied to determine scale validity. CVR assesses essentiality of an item in an instrument. For calculating this index, faculty members who were expert in the field of sexual health and STDs, rated each item as essential, useful but not essential, or not essential. Minimum acceptable value was considered higher than 0.62 . Four items were deleted in this step. To calculate content validity index, ten experts were asked to rate each item on relevance, clarity, and simplicity. The experts were requested to rate each item for relevance based on 1 ('not relevant', 'not simple', 'not clear'), 2 ('somewhat relevant', 'somewhat simple', 'somewhat clear'), 3 ('quite relevant', 'quite simple,' 'quite clear'), and 4 ('highly relevant', 'highly simple, 'highly clear'). Each CVI's item was computed as the number of experts who provided a rating of either 3 or 4 , divided by the total number of experts. Two items with CVI lover than 0.79 were omitted. Face validity was studied using a qualitative method. Ten faculty members and five women from study population were requested to assess the scales and indicate if they felt any difficulty or ambiguity in the items or responses. All comments were considered in the final version.

\section{Reliability}

Two methods were used in determination of scale reliability. First, the scales were completed by 25 women from study population. After two weeks, same women completed 
the scales again. The test-retest was calculated using Pearson's correlation coefficient $(r=0.75, p<0.001)$. The internal consistency of sub-scales was assessed by Cronbach's $\alpha$ coefficient. Cronbach's $\alpha$ coefficient was $0.77,0.82,0.74,0.75$, 0.71 , and 0.73 for knowledge, attitude, subjective norms, perceived behavioral control, intention, and preventive behaviors, respectively.

\section{Ethical consideration}

The study protocol was approved by ethics committees of the (blinded). The trial was registered in the Iranian Registry of Clinical Trials retrospectively (blinded). Before participation in the study, a written informed consent was obtained from each participant. There was no obligation to participate in the study. The participants in control group received an educational booklet after follow-up measurements.

\section{Statistical analysis}

Data was analyzed using SPSS v.16, and distribution of studied variables was tested by Schapiro-Wilk test. Because the distributions where normal, repeated measurement ANOVA was applied to evaluate time effect, group effect, and time ${ }^{\star}$ group interaction. Independent samples $t$-test, $\chi^{2}$ test and Fisher exact test was used to compare socio-economic status of the two groups. Time effect was tested first to evaluate the effect of time on both groups. Then, the group effect was evaluated to assess the effect of being in one group. Time ${ }^{\star}$ group interaction testing was performed to evaluate the effect of whole intervention through time. A significance level below 0.05 was considered in all tests.

\section{Results}

One hundred and fourteen women in the two groups completed the study. The mean \pm SD of age in the control and intervention groups was $34.26 \pm 10.87$ and $35.79 \pm 10.16$ years, respectively $(t=0.77, \mathrm{df}=112, p=0.44)$. The demographic characteristics of study subjects of the two groups are presented in Table 2. Based on the results of Table 1, two groups were homogeneous in terms of demographic characteristics.

The mean \pm SD of the planned behavior theory components is presented in Table 3. Based on the results of Table 2 the scores of all components, including knowledge, attitude, subjective norms, perceived behavioral control, intention, and behaviors changed significantly over time in both the groups (time effect). There were significant differences between the two groups in terms of scores of post- and follow-up measurements of all components (group effect). Furthermore, there were significant differences in terms of changes in scores of all components between the two groups (time* group interaction). In this regard, the scores of all domains changed more positively in the intervention subjects compared to the controls $(p<0.05)$.

\section{Discussion}

Our results showed that an educational program based on the theory of planned behavior can effectively improve the scores of knowledges, attitude, subjective norms, perceived control on behavior, and intention of women to carry

Table 2. Comparison of demographic characteristics of study subjects between two groups

\begin{tabular}{|c|c|c|c|}
\hline Group variable & Control, $n(\%)$ & Intervention, $n$ (\%) & Statistical test \\
\hline \multicolumn{4}{|l|}{ Education level } \\
\hline Lower than high school & $15(26.79)$ & $11(18.97)$ & \multirow{3}{*}{$\begin{array}{c}\chi^{2}=2.09^{\star} \\
\mathrm{df}=2.00 \\
p=0.35\end{array}$} \\
\hline High school and diploma & $32(57.14)$ & $40(68.96)$ & \\
\hline College degree & $9(16.07)$ & $7(12.07)$ & \\
\hline \multicolumn{4}{|l|}{ Job } \\
\hline Housekeeper & $36(64.29)$ & $37(63.79)$ & \multirow{2}{*}{$\begin{array}{c}\chi^{2}=2.09^{\star} \\
\mathrm{df}=2.00 \\
p=0.35\end{array}$} \\
\hline Employed & $20(35.71)$ & $21(36.21)$ & \\
\hline \multicolumn{4}{|l|}{ Perception of family income } \\
\hline Good & $24(42.86)$ & $23(39.66)$ & \multirow{2}{*}{$p=0.84^{\star *}$} \\
\hline Not good & $32(57.14)$ & $35(60.34)$ & \\
\hline \multicolumn{4}{|l|}{ Number of pregnancies } \\
\hline 0 & $8(14.29)$ & $10(17.24)$ & \multirow{4}{*}{$\begin{array}{c}x^{2}=4.20^{\star} \\
d f=3.00 \\
p=0.24\end{array}$} \\
\hline 1 & $15(26.79)$ & $16(27.59)$ & \\
\hline 2 & $22(39.29)$ & $28(48.28)$ & \\
\hline More than 2 & $11(19.64)$ & $4(6.90)$ & \\
\hline
\end{tabular}


Table 3. Comparison of mean \pm SD of planned behavior theory components scores between two groups

\begin{tabular}{|c|c|c|c|c|c|}
\hline \multirow[t]{2}{*}{ Group/time } & \multirow{2}{*}{$\begin{array}{c}\text { Control } \\
\text { (mean } \pm \text { SD) }\end{array}$} & \multirow{2}{*}{$\begin{array}{l}\text { Intervention } \\
\text { (mean } \pm S D)\end{array}$} & \multicolumn{3}{|c|}{ Repeated measurement ANOVA } \\
\hline & & & Time effect & Group effect & Time*group interaction \\
\hline \multicolumn{6}{|l|}{ Knowledge } \\
\hline Pre- & $8.03 \pm 3.92$ & $9.03 \pm 3.61$ & \multirow{3}{*}{$\begin{array}{c}\mathrm{F}(2,1.53)=399.83 \\
p>0.001\end{array}$} & \multirow{3}{*}{$\begin{array}{c}\mathrm{F}(1,112)=149.398 \\
p>0.001\end{array}$} & \multirow{3}{*}{$\begin{array}{c}F(2,1.53)=224.09 \\
p>0.001\end{array}$} \\
\hline Post- & $9.25 \pm 4.05$ & $20.03 \pm 2.38$ & & & \\
\hline Follow-up & $9.98 \pm 3.77$ & $19.58 \pm 2.86$ & & & \\
\hline \multicolumn{6}{|l|}{ Attitude } \\
\hline Pre- & $33.43 \pm 6.38$ & $33.50 \pm 8.22$ & \multirow{3}{*}{$\begin{array}{c}\mathrm{F}(2,1.63)=116.72 \\
p<0.001\end{array}$} & \multirow{3}{*}{$\begin{array}{c}\mathrm{F}(1,112)=43.30 \\
p<0.001\end{array}$} & \multirow{3}{*}{$\begin{array}{c}F(2,1.63)=102.70 \\
p<0.001\end{array}$} \\
\hline Post- & $33.80 \pm 6.72$ & $45.55 \pm 4.80$ & & & \\
\hline Follow-up & $33.96 \pm 7.72$ & $44.27 \pm 4.83$ & & & \\
\hline \multicolumn{6}{|c|}{ Subjective norms } \\
\hline Pre- & $27.33 \pm 6.82$ & $29.00 \pm 5.94$ & \multirow{3}{*}{$\begin{array}{c}\mathrm{F}(2,1.46)=116.82 \\
p<0.001\end{array}$} & \multirow{3}{*}{$\begin{array}{c}\mathrm{F}(1,112)=76.74 \\
p<0.001\end{array}$} & \multirow{3}{*}{$\begin{array}{c}\mathrm{F}(2,1.46)=82.07 \\
p<0.001\end{array}$} \\
\hline Post- & $28.50 \pm 6.34$ & $40.20 \pm 4.60$ & & & \\
\hline Follow-up & $28.12 \pm 6.53$ & $40.00 \pm 4.47$ & & & \\
\hline \multicolumn{6}{|c|}{ Perceived behavioral control } \\
\hline Pre- & $30.51 \pm 9.91$ & $30.53 \pm 6.89$ & \multirow{3}{*}{$\begin{array}{c}\mathrm{F}(2,1.41)=129.49 \\
p<0.001\end{array}$} & \multirow{3}{*}{$\begin{array}{c}\mathrm{F}(1,112)=74.69 \\
p<0.001\end{array}$} & \multirow{3}{*}{$\begin{array}{c}\mathrm{F}(2,1.41)=141.36 \\
p<0.001\end{array}$} \\
\hline Post- & $30.10 \pm 9.22$ & $48.89 \pm 8.67$ & & & \\
\hline Follow-up & $30.12 \pm 9.24$ & $48.82 \pm 7.85$ & & & \\
\hline \multicolumn{6}{|l|}{ Intention } \\
\hline Pre- & $13.50 \pm 4.99$ & $14.44 \pm 2.56$ & \multirow{3}{*}{$\begin{array}{c}\mathrm{F}(2,1.44)=245.04 \\
p<0.001\end{array}$} & \multirow{3}{*}{$\begin{array}{c}\mathrm{F}(1,112)=98.39 \\
p<0.001\end{array}$} & \multirow{3}{*}{$\begin{array}{c}\mathrm{F}(2,1.44)=123.54 \\
p<0.001\end{array}$} \\
\hline Post- & $13.66 \pm 4.82$ & $22.41 \pm 2.19$ & & & \\
\hline Follow-up & $13.57 \pm 4.79$ & $22.34 \pm 1.88$ & & & \\
\hline \multicolumn{6}{|l|}{ Behavior } \\
\hline Pre- & $51.98 \pm 11.67$ & $51.79 \pm 8.14$ & \multirow{3}{*}{$\begin{array}{c}\mathrm{F}(2,1.34)=281.87 \\
p<0.001\end{array}$} & \multirow{3}{*}{$\begin{array}{c}\mathrm{F}(1,112)=82.42 \\
p<0.001\end{array}$} & \multirow{3}{*}{$\begin{array}{c}\mathrm{F}(2,1.34)=157.78 \\
p<0.001\end{array}$} \\
\hline Post- & $52.17 \pm 11.50$ & $76.46 \pm 6.62$ & & & \\
\hline Follow-up & $51.89 \pm 11.48$ & $75.62 \pm 6.27$ & & & \\
\hline
\end{tabular}

out healthier sexual behaviors. Also, our results revealed that the study subjects showed healthier sexual behaviors after intervention. Knowledge is not a construct of the planned behavior theory. The effect of education on the increase of knowledge towards STDs was assessed in several studies. A study by Allen [25] among college students showed that video education was effective in the increase of knowledge of preventing sexually transmitted infections. A study conducted by Goldsberry et al. [26] on fraternity and sorority members demonstrated that a brief STDs educational intervention based on TPB can increase STDs knowledge. Results of another study in Kenya also showed that educational intervention based on the planned behavior theory was effective in increasing knowledge about HIV prevention [27]. Increasing knowledge is usually associated with improved attitudes towards health behaviors [28]. There has also been a positive link between increase of knowledge and desire for health behaviors, such as vaccination against HPV [29].

Similar to the results of the present study, the application of planned behavior theory in various studies has been associated with an increase of healthy sexual health behaviors.
A study by Tseng et al. [30] in China revealed that the constructs of TPB were powerful predictors of safe sexual behavior's intention among females youth. Moreover, a study by Jalambadani et al. [17] on the effect of sex education based on TPB in married women on knowledge and false beliefs about sexual relationships, showed that the score of knowledge, attitude, perceived behavioral control, and intention to sexual function in the education group increased significantly.

Our results showed that, along with the increase in knowledge and improvement in attitude of women on healthy sexual behaviors, the scores of subjective norms and perceived behavioral control increased as well. The spouses of our study subjects were participating in the educational program, which was an effective factor. This result was confirmed in previous studies. Chowdhuri et al. [15] conducted a study to assess how knowledge and perceptions of condoms and partners' communication influence the use of condoms in a high HIV prevalence setting in Zambia. Their results showed that partners' communication was associated with over three times higher odds of condom use. 
Another study [31] showed that a training package based on TPB was effective in the improvement of genital self-image and sexual function of married women in Iran. Their results also demonstrated that spouse's participation was effective in sexual function of married women. Sexual dysfunction in women was higher in women who had poor communication with their spouses. In another study [32] on married women in Iran, sexual health education based on TPB was effective in improving female sexual function. Their results showed that the quality of sexual relationship was related to better sexual function. Quality of life is related with social desirability and better social support which can increase the likelihood of preventive behaviors [33].

The results of the present study also showed an improvement in the intention and behavior of women, which is consistent with previous studies [17-20, 30].

\section{Limitations}

The main limitation of the present study was the method and location of sampling. Using convenient sampling may reduce generalizability of results. Also, all participants were married women attending one center. Furthermore, in Iran a large number of women use private sector services, and this can negatively affect generalizability of our results. Additional studies are needed to confirm and elaborate our findings in women in general population. The second limitation was that we used self-reported data, which relies on accurate recall and trustworthiness of study subjects. We suggest to use other methods of data collection, with a questionnaire in future studies, to assess behavior of subjects.

\section{Conclusions}

Our results showed that an educational program based on the theory of planned behavior is effective in the improvement of knowledge, attitude, subjective norms, perceived control on behavior, intention, and actual healthy sexual behaviors. These results indicate that our intervention caused an awareness in married women, which are at risk of sexually transmitted diseases. Our results suggest that several factors must be considered to promote healthy sexual behavior in married women. Involving spouses in the program was a strength of the present study, which could have a positive effect on all the constructs of theory of planned behavior. The results of the present study can be used in educational planning for married women. We suggest that women would participate in training programs with their partners. Also, we recommend comparing this theory with other models and theories in future studies to choose the best method of education. Moreover, evaluation of effectiveness of this method in more at-risk groups, such as sex workers or addicts, is also recommended.

\section{Funding}

The study was a thesis approved MSc of the Tehran University of Medical Sciences that funded the study as a research project in data collection phase.

\section{Acknowledgements}

This study was a part of a MSc. This research did not receive any specific grant. The authors want to thank all study participants for their involvement.

\section{Conflict of interest}

The authors declare no conflict of interest.

\section{References}

1. Sieving RE, Gewirtz O’Brien JR, Saftner MA, Argo TA. Sexually transmitted diseases among US adolescents and young adults: patterns, clinical considerations, and prevention. Nurs Clin North Am 2019; 54: 207-225.

2. World Health Organization. Global health sector strategy on sexually transmitted infections 2016-2021: toward ending STIs. Geneva: World Health Organization; 2016.

3. Amiri FB, Mostafavi E, Mirzazadeh A. HIV, HBV and HCV coinfection prevalence in Iran - a systematic review and meta-analysis. PLoS One 2016; 11: e0151946.

4. Kushwaha B, Gupta G. Sexually Transmitted Infections and Male Infertility: Old Enigma, New Insights. In: Male Infertility: Understanding, Causes and Treatment. Springer; 2017. pp. 183-212.

5. Vinodhini K, Shanmughapriya S, Das BC, Natarajaseenivasan K. Prevalence and risk factors of HPV infection among women from various provinces of the world. Arch Gynecol Obstet 2012; 285: 771-777.

6. Sonnenberg P, Johnson A. Sexually transmitted infections: epidemiology and control. In: Abubakar I, Stagg H, Cohen T, Rodrigues L (eds.). Oxford Specialist Handbook of Infectious Disease Epidemiology. New York: Oxford University Press; 2016.

7. Sadler S, Tosh J, Pennington R, et al. A cost-effectiveness analysis of condom distribution programmes for the prevention of sexually transmitted infections in England. J Epidemiol Community Health 2017; 71: 897-904.

8. Rahimzadeh S, Naderimagham S, Rohani-Rasaf M, et al. Burden of sexually transmitted infections in Iran from 1990 to 2010: results from the Global Burden of Disease study 2010. Arch Iran Med 2016; 19: 768-773.

9. Tan RKJ, Kaur N, Kumar PA, et al. Clinics as spaces of costly disclosure: HIV/STI testing and anticipated stigma among gay, bisexual and queer men. Cult Health Sex 2020; 22: 307-320.

10. Ma W, Wu G, Zheng H, et al. Prevalence and risk factors of HIV and syphilis, and knowledge and risk behaviors related to HIV/ AIDS among men who have sex with men in Chongqing, China. J Biomed Res 2016; 30: 101-111.

11. Azien I, Fishbein M. Understanding attitudes and predicting behaviors. Englewoods Cliffs, NJ: Prentice Hall; 1980.

12. Ajzen I. From intention to action: a theory of planned behaviour. In: Kuhl J, Beckman J (eds.). Action Control: From Cognition to Behaviour. New York, NY: Springer; 1985. pp. 11-39.

13. Ajzen I, Madden TJ. Prediction of goal-directed behavior: attitudes, intentions, and perceived behavioral control. J Exp Soc Psychol 1986; 22: 453-474.

14. Ajzen I. Attitudes, traits, and actions: dispositional prediction of behavior in personality and social psychology. In: Berkowitz L (ed.). Advances in Experimental Social Psychology. New York: Academic Press; 1987. pp. 1-63. 
15. Chowdhuri RN, Pinchoff J, Boyer CB, Ngo TD. Exploring gender and partner communication: theory of planned behavior predictors for condom use among urban youth in Zambia. Int J Gynaecol Obstet 2019; 147: 258-267.

16. Guan M, Coles VB, Samp JA, Sales JM, DiClemente RJ, Monahan JL. Incorporating communication into the theory of planned behavior to predict condom use among African American women. J Health Commun 2016; 21: 1046-1054.

17. Jalambadani Z, Garmarodi G, Tavousi M. Sex education of married women based on theory of planned behavior. CHRISMED J Health Res 2017; 4: 180-185.

18. Khani Jeihooni A, Kouhpayeh A, Najafi S, Bazrafshan MR. Application theory of planned behavior on promotion of safe sexual behaviors among drug users. Journal of Substance Use 2018; 24: 293-299.

19. Moeini B, Hazavehei SMM, Zareban I, et al. Effectiveness of an educational program based on the theory of planned behavior for improving safe sexual behaviors intention among addicted males: a quasi experimental study. Int J High Risk Behav 2017; 6: e32432.

20. Ji EM, Choi SY, Je NJ. A structural equation modeling on reproductive health promoting behavior of unmarried women: based on the theory of planned behavior. Korean J Women Health Nurs 2016; 22: 210-220.

21. Shepherd LM, Sly KF, Girard JM. Comparison of comprehensive and abstinence-only sexuality education in young African American adolescents. J Adolesc 2017; 61: 50-63.

22. Turchik JA, Gidycz CA. Prediction of sexual risk behaviors in college students using the theory of planned behavior: a prospective analysis. J Soc Clin Psychol 2012; 31: 1-27.

23. Ma W, Kang D, Song Y, Wei C, Marley G, Ma W. Social support and HIV/STDs infections among a probability-based sample of rural married migrant women in Shandong Province, China. BMC Public Health 2015; 15: 1170.

24. Kalia N, Singh J, Sharma S, Kamboj SS, Arora H, Kaur M. Prevalence of vulvovaginal infections and species specific distribution of vulvovaginal candidiasis in married women of north india. Int J Curr Microbiol App Sci 2015; 4: 253-266.

25. Allen W. Increasing knowledge of preventing sexually transmitted infections in adult college students through video education: an evidenced-based approach. ABNF Journal 2017; 28: 64-68.

26. Goldsberry J, Moore L, MacMillan D, Butler S. Assessing the effects of a sexually transmitted disease educational intervention on fraternity and sorority members' knowledge and attitudes toward safe sex behaviors. J Am Assoc Nurse Pract 2016; 28: 188-195.

27. Harper GW, Muthigani A, Neubauer LC, et al. The development and evaluation of a national school-based HIV prevention intervention for primary school children in Kenya. J HIV AIDS 2018. DOI: 10.16966/2380-5536.150.

28. Moore DC. Attitudes and Knowledge about Sexually Transmitted Diseases and Condom Use Among College Students Ages 18-25. Mississipi, US: Alcorn State University; 2017.

29. Johnson C, Ogletree R. Knowledge and behavioral intention related to HPV vaccination among male college students. Am J Health Educ 2017; 48: 320-330.

30. Tseng YH, Cheng CP, Kuo SH, Hou WL, Chan TF, Chou FH. Safe sexual behaviors intention among female youth: the construction on extended theory of planned behavior. J Adv Nurs 2020; 76: 814-823.

31. Ramezani Tehrani F, Farahmand M, Mehrabi Y, Malek Afzali H, Abedini M. Prevalence of female sexual dysfunction and its correlated factors: a population based study. Payesh Journal 2012; 11: 869-875.

32. Sabeti F, Sadat-Tavafian S, Zarei F. The effect of educational intervention on sexual function of women referred to health center of south of Tehran. Nursing Practice Today 2018; 5: 280-289.

33. Arab M, Kohan M, Ranjbar H, Arab N, Rayani M, Mirrashidi SS, Rafiei H, Amiri M. Quality of life, social desirability and their relationship in opium addicted persons in southeast of Iran. Glob J Health Sci 2014; 6: 97-103. 